\title{
Impactos na trajetória de egressos do Curso Técnico em Agropecuária da Escola
}

\section{Técnica Agrícola Vale da Uva Goethe}

\author{
Impacts on the trajectory of graduates of the Technical Course in Agriculture at the Vale of Uva
}

\author{
Goethe Agricultural Technical School
}

Impactos en la trayectoria de los egresados del Curso Técnico en Agricultura de la Escuela Técnica

Agrícola Vale da Uva Goethe

Recebido: 13/10/2020 | Revisado: 20/10/2020 | Aceito: 13/07/2021 | Publicado: 20/07/2021

\author{
Walquíria Guedert Mendes \\ ORCID: https://orcid.org/0000-0003-1970-1379 \\ Instituto Federal de Educação, Ciência e Tecnologia de Santa Catarina, Brasil \\ E-mail: walquiria.guedert@gmail.com \\ Roberta Pasqualli \\ ORCID: https://orcid.org/0000-0001-8293-033X \\ Instituto Federal de Educação, Ciência e Tecnologia de Santa Catarina, Brasil \\ E-mail: roberta.pasqualli@ifsc.edu.br
}

\begin{abstract}
Resumo
A pesquisa apresentada tem como objetivo analisar o impactos nas trajetórias profissionais dos egressos do Curso Técnico em Agropecuária Integrado ao Ensino Médio da Escola Técnica Vale da Uva Goethe. Metodologicamente, esta pesquisa se apresenta como sendo de natureza aplicada com abordagem qualitativa, caracterizada como pesquisa do tipo descritiva, com uma dimensão exploratória. A execução da presente pesquisa se deu por meio de estudo de caso, tendo por base os trabalhos de Yin (2005). Participaram da pesquisa egressos do Curso Técnico em Agropecuária Integrado ao Ensino Médio da Escola Técnica Agrícola Vale da Uva Goethe. Como instrumento de coleta de dados foi aplicado um questionário compostos de questões de ordem interpessoal, elencando os principais contextos da estrutura do curso e a sua importância para o egresso. Identificou-se as expectativas dos egressos quanto ao curso, valorizando suas experiências. De forma geral, o impacto do curso foi altamente relevante e positivo em sua vida acadêmica e profissional. O nível e a intensidade do impacto do curso na vida dos egressos são diferenciados, porque também são distintas as experiências e vivências de cada sujeito. Assim, essa diversidade favoreceu a troca de experiências entre os estudantes, acrescentando novos conhecimentos e repercutindo nos impactos propiciados pelo curso técnico.
\end{abstract}

Palavras-chave: Educação profissional e tecnológica; Aluno egresso; Curso técnico em agropecuária.

\begin{abstract}
The research presented aims to analyze the impacts on the professional trajectories of the graduates of the Technical Course in Agricultural Integrated to High School of the Technical School Vale da Uva Goethe. Methodologically, this research presents itself as being of an applied nature with a qualitative approach, characterized as descriptive research, with an exploratory dimension. This research was carried out through a case study, based on the work of Yin (2005). Participated in the research graduates of the Technical Course in Agricultural Integrated to High School of the Agricultural Technical School Vale da Uva Goethe. As a data collection instrument, a questionnaire composed of interpersonal questions was applied, listing the main contexts of the course structure and its importance for graduates. Expectations of graduates regarding the course were identified, valuing their experiences. In general, the impact of the course was highly relevant and positive in his academic and professional life. The level and intensity of the impact of the course on the graduates' lives are different, because the experiences and experiences of each subject are also different. Thus, this diversity favored the exchange of experiences among students, adding new knowledge and reflecting on the impacts provided by the technical course.
\end{abstract}

Keywords: Professional and technological education; Graduate student; Technical course in agriculture.

\section{Resumen}

La investigación presentada tiene como objetivo analizar los impactos en las trayectorias profesionales de los egresados del Curso Técnico en Agropecuario Integrado al Bachillerato de la Escuela Técnica Vale da Uva Goethe. Metodológicamente, esta investigación se presenta como de naturaleza aplicada con enfoque cualitativo, caracterizada como investigación descriptiva, con una dimensión exploratoria. Esta investigación se realizó mediante un estudio de caso, basado en el trabajo de Yin (2005). Participó en la investigación de los egresados del Curso Técnico en 
Agropecuario Integrado al Bachillerato de la Escuela Técnica Agrícola Vale da Uva Goethe. Como instrumento de recolección de datos, se aplicó un cuestionario compuesto por preguntas interpersonales, enumerando los principales contextos de la estructura del curso y su importancia para los egresados. Se identificaron las expectativas de los egresados con respecto al curso, valorando sus experiencias. En general, el impacto del curso fue muy relevante y positivo en su vida académica y profesional. El nivel e intensidad del impacto del curso en la vida de los egresados es diferente, porque las vivencias y vivencias de cada asignatura también lo son. Así, esta diversidad favoreció el intercambio de experiencias entre los estudiantes, agregando nuevos conocimientos y reflexionando sobre los impactos que brindó el curso técnico.

Palabras clave: Educación profesional y tecnológica; Estudiante de postgrado, Curso técnico en agricultura.

\section{Introdução}

A Escola Técnica Vale da Uva Goethe está localizada no Distrito de Azambuja, Pedras Grandes - SC, foi local do assentamento dos primeiros imigrantes italianos no Brasil. A escola foi mantida de 2012 até o final de 2019 pela Universidade Barriga Verde - Unibave e os estudantes são, de acordo com dados da própria instituição, na sua maioria, filhos de agricultores.

A agricultura é a base econômica do município e, na cultura local, percebemos traços dos costumes que os imigrantes italianos trouxeram do século passado, tais como a dança, a fala e as festas. A partir disto, e pensando na população do entorno do município, é que o Curso Técnico em Agropecuária Integrado ao Ensino Médio da Escola Técnica Vale da Uva Goethe foi criado.

A formação para o desenvolvimento da propriedade familiar justifica-se por ser uma realidade de nosso estado, conforme registrado por Altmann (2010, p. 112):

Santa Catarina é um dos seis principais Estados brasileiros produtores de alimentos, apresentando em diversas atividades as mais altas produtividades do país. O setor agrícola contribui com 12,8\% na formação do PIB e ocupa cerca de 700 mil pessoas. O número de agroindústrias está estimado em 3 mil estabelecimentos que mantém mais de 76 mil empregos. O Estado é importante exportador de alimentos e produtos agrícolas, em especial carnes, frutas, fumo e produtos do setor florestal. A agricultura catarinense é hegemonicamente familiar, sendo constituída por cerca de 180 mil estabelecimentos, representando mais de $90 \%$ do total de estabelecimentos agropecuários. (Altmann, 2010, p. 112).

A atual realidade das famílias de propriedades agrícolas vem acompanhada de resultados que muitas vezes afastam o produtor da sua atividade fim e que, segundo Camarano (2006), coloca em risco a continuidade das atividades na agricultura familiar.

Morar na região rural é uma variável importante, principalmente para os jovens e adolescentes, pois influencia na decisão de frequentar a escola e, por consequência, estar fora das discussões qualificadas acerca do mundo do trabalho. "[...] Entre os homens, verificou-se que a proporção dos que não estudavam e não estavam no mercado de trabalho era mais alta entre os residentes no meio rural, 10,5\%, que nas áreas urbanas, 6,7\% [...]”. (Camarano, 2006, p. 267).

Sabe-se que a qualificação no meio rural também é necessária para o conhecimento e preparação qualificada dos recursos humanos e que isto propicia oportunidades, principalmente aos pequenos agricultores. Destaca-se, também, que o êxodo rural vem aumentando devido à falta de capacitação profissional para os jovens rurais e a falta de oportunidade, pois há escassez de alternativas para o jovem campo e as poucas oportunidades de trabalho e de estudo para esses jovens favorecem a migração para as cidades maiores.

Os jovens que estão no campo não possuem atrativos e incentivos para adequar suas condições de vida com a produção familiar, evolução essa que exige-se nos demais setores. O conhecimento desses jovens está condicionado e baseado nas experiência de seus familiares e, do conhecimento popular, dificultando a aplicação de técnicas fomentadas no meio escolar. 
Ao perceber a necessidade da população agrícola, os próprios órgãos do governos governo sugerem escolas direcionadas a atividade agrícola e, com isso, a Fundação Educacional Barriga Verde - FEBAVE tomou a iniciativa de oferecer o Curso Técnico em Agropecuária Integrado ao Ensino Médio, no turno noturno, para que os estudantes pudessem trabalhar durante o dia, pois é notório que a cidade de Pedras Grandes respira agricultura e agropecuária. Sabe-se que a maioria das propriedades rurais da Região de Pedras Grandes, é feita pela agricultura familiar e que as atividades relacionadas a agricultura são as responsáveis pela produção das riquezas que impulsionam a região. Portanto, o Curso Técnico em Agropecuária Integrado ao Ensino Médio teve como premissa promover o crescimento territorial, com ênfase no desenvolvimento das propriedades agrícolas familiares, sem desvalorizar as necessidades formativas, para que os estudantes pudessem atuar em outras realidades.

Baseado na filosofia de atender o homem do campo e, assim, incentivar seus filhos a ajudá-los sem precisar sair da propriedade rural, o Curso Técnico em Agropecuária Integrado ao Ensino Médio tem como premissa as necessidades dos produtores rurais do município de Pedras Grandes e região para suprir as indispensabilidades que precisam ser atendidas.

Nesta direção, a sequência deste texto discorre sobre os impactos do Curso Técnico em Agropecuária da Escola Técnica Agrícola Vale da Uva Goethe na trajetória de seus egressos.

\section{Metodologia}

A pesquisa apresentada neste texto é de natureza aplicada com abordagem qualitativa, caracterizada como pesquisa do tipo descritiva, com uma dimensão exploratória. A execução da presente pesquisa se deu por meio de estudo de caso, tendo por base os trabalhos de Yin (2016). Em geral, estudos de caso são as estratégias preferidas quando as questões 'como' ou 'por que' estão presentes, quando o investigador tem um pequeno controle sobre os eventos, e quando o foco é no fenômeno contemporâneo entre alguns contextos da vida real. A pesquisa foi realizada com os egressos do Curso Técnico em Agropecuária Integrado ao Ensino Médio e teve como locus a Escola Técnica Vale da Uva Goethe, localizada no Distrito de Azambuja, Pedras Grandes - SC, que foi local do assentamento dos primeiros imigrantes italianos no Brasil.

Gatti discorre muito bem sobre essa questão do uso das abordagens quantitativas e qualitativas:

Os métodos de análise de dados que se traduzem por números podem ser muito úteis na compreensão de diversos problemas educacionais. Mais ainda, a combinação deste tipo de dados com dados oriundos de metodologias qualitativas, podem vir a enriquecer a compreensão de evento, fatos, processos. As duas abordagens demandam, no entanto, o esforço da reflexão do pesquisador para dar sentido ao material levantado e analisado. (Gatti 2004, p. 13).

De um universo de 70 estudantes formados destaca-se que a amostra dos sujeitos da pesquisa foram 33 estudantes egressos de 05 turmas do Curso Técnico em Agropecuária Integrado ao Ensino Médio da Escola Vale da Uva Goethe, formados nos anos de 2014, 2015, 2016, 2018 e 2019.

O instrumento utilizado para a coleta de dados da pesquisa empírica foi um questionário aplicado pela pesquisadora no mês de fevereiro de 2020. Para a análise dos dados os participantes foram identificados pela letra ' $E$ ' de egresso e, número em ordem crescente de entrevistas analisadas a partir de ' 01 ' a ' 33 '. Foi realizado o agrupamento temático das falas correspondentes a cada questão da entrevista, criando-se assim as categorias de análise.

É sobre o desenvolvimento desta metodologia que a sequência do texto versa. 


\section{Curso Técnico em Agropecuária Integrado ao ensino médio da Escola Técnica Agrícola Vale da}

\section{Uva Goethe: impactos na trajetória dos egressos}

\subsection{Organização do currículo escolar em agropecuária}

O currículo da Escola Técnica Agrícola Vale da Uva Goethe foi pensado para atender as propriedades rurais da região e, por isso, ele foi dividido em regime seriado, com unidades curriculares anuais e duração mínima de três anos. Cada estudante era matriculado na primeira série pois todas as unidades curriculares eram pré-requisitos para os anos seguintes.

A proposta do Curso Técnico em Agropecuária Integrado ao Ensino Médio era completar a teoria com a prática, priorizando um cidadão crítico e sujeito de transformação em seu meio, na busca de um mundo melhor, e por isso o currículo tornou-se articulado ao ensino médio. Para Pasqualli, Silva e Silva (2019) é fundamental analisar se a formação proposta no currículo do curso encontra-se voltada para o mundo do trabalho. Se o mesmo prevê uma formação integral humanista, ou se simplesmente propõem uma formação de mão de obra para o mercado de trabalho.

Os conteúdos curriculares eram divididos em dois segmentos: Conteúdos Básicos e Conteúdos Profissionalizantes. O primeiro é responsável pelos conhecimentos referentes ao ensino médio, enquanto o segundo é o que caracteriza o curso, dando a identidade profissional que o estudante procura.

Haviam reuniões para articular as unidades curriculares do ensino propedêutico e da área técnica e, com isso, propiciar a troca de ideias e um planejamento articulado.

As aulas eram realizadas no período noturno e aos sábados pela manhã, para complementar a carga horária necessária do currículo. As unidades curriculares práticas acorriam em propriedades rurais da região, estabelecendo vínculos entre a escola e a comunidade.

\subsection{Perfil do estudante do Curso em Agropecuária}

De acordo com o Projeto Político Pedagógico (PPC) do Curso Técnico em Agropecuária Integrado ao Ensino Médio, o estudante que concluir o curso está habilitado para atuar de forma criativa, inovadora e comprometida com a sustentabilidade agrícola, podendo gerenciar uma propriedade e até prestar serviços de assistência técnica para demais propriedades rurais, empresas do setor, cooperativas e demais instituições. Nessa atuação, ou como autônomo ou com vínculo a uma empresa, o profissional poderia desenvolver ações que estão relacionadas à análise das características econômicas, sociais e ambientais, identificando as atividades de planejamento, execução e condução de projetos no ramo da agropecuária. Segundo Lima (2000):

O projeto pedagógico da escola, na realidade, cada vez mais se ajusta à modernidade, para atender à demanda do mundo do trabalho. Tal projeto institucional estaria mais próximo da reprodução social. A escola, sem excluir outros projetos, deveria ter fortemente o seu trabalho pedagógico em função de intervenção, numa realidade regional cuja principal atividade é a agricultura familiar. Consequentemente, se não presta a atenção ao seu cenário imediato, estará promovendo muito mais a formação de um profissional acrítico, fruto de uma aprendizagem que capacita-o para: confirmar observações, memorizar, aprender respostas e só saber se alguém ensinar. Ao contrário disso deve se questionar quanto ao investimento pedagógico que deveria ter em vista a formação de um técnico agrícola capacitado cognitivamente para: observar, saber-ver, saber-fazer, analisar, questionar, argumentar, descobrir, etc. E assim, pronto para a inserção no mundo produtivo, como sujeito crítico e criativo. Com atitudes adequadas para as exigências do que o sistema produtivo mais democrático que contemplasse: pequenos, grandes proprietários e até os sem propriedade. (Lima 2000, p. 9-10).

Com um PPC voltado para a área técnica em Agropecuária, a mantenedora promoveu uma formação profissional que antes não existia na região, onde prepondera a atividade agrícola familiar, então, com a abertura do curso técnico, integrado com o ensino médio regular, os estudantes da região de Azambuja - Pedras Grandes e cidades vizinhas, viram a oportunidade 
de agregar o conhecimento teórico com o prático com um atrativo a mais: estudar em uma escola particular com bolsa integral para os três anos do curso.

A primeira turma do Curso Técnico em Agropecuária Integrado ao Ensino Médio teve início em 2012 e a sua maioria eram estudantes com idade entre 15 e 20 anos. Vários estudantes tiveram interesse, porém no processo de seleção, apenas trinta foram escolhidos. Percebeu-se que muitos dos matriculados já tinham o ensino médio concluso, mas um dos estudantes chamou atenção, pois estava concluindo concomitantemente, ou seja, fazia o ensino médio no período matutino e no noturno o técnico.

As turmas subsequentes foram mistas, haviam estudantes matriculados que já estavam formados, mas com o intuito do aprendizado técnico e, outros, que vieram do ensino fundamental.

As empresas e as pequenas propriedades souberam do curso e, em 2013, a escola começou a informar os nomes dos estudantes que faziam o curso, passando a ter um cadastro, onde os produtores ou empresas que precisavam dos serviços dos técnicos ligavam para a secretaria da Unidade Escolar e solicitavam indicações. Alguns deixavam uma ficha para que os interessados preenchessem para posteriormente fazerem uma de entrevista de emprego.

Mesmo após a conclusão do curso percebeu-se que as empresas continuavam mantendo contato com a Escola, para que a mesma divulgasse aos estudantes as vagas de emprego disponíveis.

Os estudantes que lá estudaram, eram oriundos de várias comunidades, inclusive de uma cidade nas imediações de Pedras Grandes. Quanto aos professores a maioria residia em cidades vizinhas.

Sabe-se que, no ato da matrícula do Curso Técnico em Agropecuária Integrado ao Ensino Médio da Escola Técnica Agrícola Vale da Uva Goethe os estudantes preenchiam um questionário informando dados pessoais, endereço e autorizações possibilitando a mantenedora fazer o acompanhamento quanto às localidades que têm interesse no curso.

De acordo com os dados obtidos nestes questionários, os estudantes que decidiam fazer o Curso Técnico em Agropecuária Integrado ao Ensino Médio eram, principalmente, filhos de agricultores que moravam na região de Azambuja Pedras Grandes, além de profissionais que trabalhavam em agropecuárias e que querem unir o conhecimento prático ao teórico.

\subsection{A importância da Escola Agrícola Vale da Uva Goethe na visão dos alunos egressos}

A agricultura, no Brasil, passa por várias fases que são refletidas no mercado de trabalho dos técnicos agrícolas, onde percebemos que a agricultura se apresenta em desenvolvimento, seja em expansão ou seja em tecnologia.

Podemos perceber que o rumo da agricultura influencia o mercado de trabalho do técnico agrícola e, com as transformações tecnológicas no campo, evidenciou-se para a atualização dos técnicos agrícola e com o Decreto no 4.560 de 30 de dezembro de 2002, que segundo Barbosa (2010) proporcionou "consistência à profissão em condições de competir com as outras profissões no setor agropecuário, com a possibilidade de exercer importantes atribuições e com sua capacidade profissional ocupar o devido espaço no mercado de trabalho".

Com a ascensão dos cursos técnicos, principalmente os agrícolas, a universidade UNIBAVE viu a possibilidade de investimento para tal mercado e, assim, percebeu-se que o Curso Técnico em Agropecuária deveria, também, voltar-se para o empreendedorismo e ampliar a visão crítica dos estudantes, tal a compreender o mundo que o cerca, seja como empreendedor ou empregado.

Sendo assim, iniciamos a análise dos dados coletados com 33 egressos do curso de um universo de 70 egressos total.

Com relação à idade dos egressos destaca-se que $60,6 \%$ possui de 19 a 21 anos, $4,2 \%$ possui de 22 a 24 anos, $6,1 \%$ possui de 25 a 27 anos, $6,1 \%$ possui de 28 a 30 anos e $3 \%$ possui mais de 31 anos. 
Quanto ao ano de conclusão do curso, observou-se que 17\% conclui em 2014, $23 \%$ conclui em 2015, 13\% conclui em 2016, 20\% conclui em 2018 e, $27 \%$ conclui em 2019.

Quando questionados sobre 'Você acredita que o curso Técnico de Agropecuária Integrado ao Ensino Médio realizado na Escola Técnica Agrícola Vale da Uva Goethe teve um impacto maior em sua vida do que se você tivesse cursado Ensino Médio Regular? Se sim, porquê? obtivemos as seguintes respostas representativas':

Sim, pois o curso me proporcionou muito conhecimento na área agrícola e me abriu grandes portas profissionais. (E 01).

Sim, apesar de puxado e corrido, foi algo satisfatório para mim, foi lá onde conheci pessoas incríveis, tive um aprendizado que jamais teria se tivesse continuado no meu antigo colégio e sem dúvida abriu minha mente para um mundo completamente novo, que eu jamais imaginaria que iria explorar e gostar, estou muito satisfeito. (E02).

Sim, pois além de ter algo a mais em nosso currículo, temos a grandiosa chance de ingressar no mercado de trabalho no ramo agropecuário, pois nos formamos neste meio. (E 06).

Sim, pois pude melhorar a abrangência das áreas de atuação, além de agregar de forma qualitativa os conhecimentos obtidos através do curso, nas viagens e saídas a campo, onde tivemos o privilégio de realizar uma troca de conhecimento com os produtores que nos receberam. (E 15).

Sim, acredito que tiveram pontos positivos em relação a ter um contato maior com Estágios e relatórios de estágios, porém em relação as matérias de ensino médio teria sido mais viável ter frequentado uma escola de ensino médio regular pois as matérias eram muito vagas, tínhamos que fazer avaliações toda noite para obter as notas no pequeno período de aulas e isso consumia muito tempo que poderia ser utilizado para explicações mais aprofundadas. (E 27).

Analisando as respostas dos egressos, constatou-se que a maioria foi unânime em responder que houve, de fato, um impacto positivo na vida dos cursistas, quando relacionado ao curso técnico. Consideraram proveitosa e construtiva a experiência de cursar ensino médio técnico ao invés do ensino regular.

Oliveira (2009, p. 44) faz uma observação quanto o enfoque mais profundo na "formação de sujeitos mais capazes de competir por uma vaga no mercado de trabalho, considerados peças fundamentais no processo de desenvolvimento econômico da nação".

Os egressos afirmaram que curso técnico agregou conhecimentos na área agrícola e abriu grandes portas profissionais. Relataram que abriu a mente para um mundo completamente novo, algo a mais no currículo, expandindo a área de atuação e projetando-os para uma nova área a ser explorada, e assim, poderiam ingressar no mercado de trabalho, agropecuário, que é um setor primário e promissor.

Nesta direção, Frigotto (2007, p. 1146) destaca que:

[...] o diferencial está na proposta política e pedagógica da escola, centrada no debate e na concepção da escola unitária e politécnica; uma escola comprometida em formar jovens que articulem ciência, cultura e trabalho e lhes dê a possibilidade de serem cidadãos autônomos; que possam escolher seguir seus estudos ou, se têm necessidade, ingressar na vida profissional. (Frigotto, 2007, p. 1146).

Os egressos descreveram as saídas de campo como uma grande oportunidade de conhecimentos qualitativos e esclarecedores pois, encontravam-se no ambiente real e, trocaram proveitosas e esclarecedoras experiências diretamente com os produtores durante esse estágio. 
Houve, porém, uma resposta em que o egresso relata uma experiência totalmente negativa e contrária, aos objetivos e propostas do curso técnico. Ele descreve um impacto negativo pois, para ele, o curso trouxe um atraso em sua vida acadêmica, considerou o ensino médio fraco com várias falhas nas disciplinas, e assim teve que buscar ajuda para conseguir completar as disciplinas acadêmicas. O egresso ainda relatou que o técnico foi tão fraco que durante a graduação não fez a menor diferença e não agregou nenhum tipo de conhecimento ao seu currículo.

Sim. Teve maior impacto negativo, demorei entender que o curso trouxe um atraso em minha vida acadêmica, ao contrário do que acreditava. O ensino médio fraco me deixou com uma formação falha em várias disciplinas que eu tive que buscar ajuda para conseguir completar as disciplinas acadêmicas. $O$ técnico foi tão fraco que durante a graduação não fez a mínima diferença. (E 19).

A resposta do egresso vem reforçar as afirmações de Kuenzer (2000), que já dizia: é preciso uma democratização concreta, no Ensino Médio, que prepare o estudante tanto para a inserção no mundo do trabalho quanto para a cidadania e que acrescente nos níveis a seguir, para a formação profissional científico e tecnológica e sócio-histórica, assim como está proposta na legislação, onde exige situações nas quais não são oferecidas no caso brasileiro.

Quando questionados sobre 'Você considera que a realização do curso Técnico de Agropecuária Integrado ao Ensino Médio realizado na Escola Técnica Agrícola Vale da Uva Goethe foi importante para sua vida? Sim? Não? Se sim, descreva a importância’ observamos que 94\% identificou que o curso Técnico de Agropecuária Integrado ao Ensino Médio realizado na Escola Técnica Agrícola Vale da Uva Goethe foi importante em suas vidas, enquanto 4\% disseram que não teve nenhuma importância, onde as justificativas para essas respostas foram:

Ele me engrandeceu em conhecimento, em amadurecimento e me mostrou o papel fundamental que o agro tem na vida de todas as pessoas. Fazer o técnico em agropecuária me fez valorizar cada um dos alimentos que chegam a nossa mesa e as pessoas envolvidas por trás disso. (E 30).

Me tornei técnica em agropecuária; Aprimorei meus conhecimentos práticos e teóricos no ramo agropecuário; Melhor entendimento sobre o homem do campo; Conhecimento de produções; Conhecimento de vários profissionais que nos fizeram aprimorar nossos conhecimentos em diversas áreas. (E 25).

Me fez ter certeza de que queria a graduação em agronomia na qual estou agora. Além de, possuir uma carga horária maior do que somente o ensino médio proporcionando conhecimento em muitas áreas que agregaram para a minha vida. (E 20).

Foi importante como Responsabilidade, vocês respeita mais a agricultura e o produtor, Aprende coisas que nunca imaginaria aprender, $O$ curso ele te abre oportunidades de emprego e oportunidades de saber exatamente se você quer engrossar uma faculdade e qual faculdade, E você não faz uma turma ou uma amizade, Você faz uma família, $E$ que você sente saudade. (E 31).

Para alguns egressos é questionável a eficiência do curso Técnico de Agropecuária Integrado ao Ensino Médio. Em pesquisas sobre o assunto, identificou-se que alguns cursos técnicos foram implantados com a função de preparar os alunos, primeiramente através de conhecimentos teóricos para posteriormente desenvolver, na prática, os conhecimentos experienciados, e assim capacitando-os para o mercado de trabalho, assim como Oliveira (2009, p. 54) nos diz que: 
O Ensino Médio Integrado (EMI) não deve ser palco para desenvolvimento de competências ou de habilidades preconizadas no discurso empresarial. Essa etapa da Educação Básica não pode e não deve estar voltada para o aumento da produtividade tão em voga em momento atual. O EMI deve ser considerado um espaço/tempo de superação, no plano formativo, da fragmentação imposta pela divisão social do trabalho. (Oliveira, 2009, p. 54).

Partindo desse pressuposto, Ciavatta e Rummert (2010) considera o Ensino Médio Integrado como um grande desafio do atual governante do país, tanto em efetivá-lo quanto em implementá-lo. Podemos dizer que as expectativas foram concretizadas, pois ao ler e analisar os depoimentos dos egressos, foi possível constatar quais resultados apresentaram retorno aos cursistas, o que foi notoriamente percebido quando, uma aluna relatou que o Curso Técnico em Agropecuária a engrandeceu em conhecimento, amadurecimento e considerou como fundamental o ‘agro' na vida das pessoas.

Na sequência, quando questionados sobre 'Você acredita que este curso é importante também para a região? Sim? Não? Se sim, porquê?', foram obtidos os seguintes percentuais: 94\% dos entrevistados disseram que o curso teve relevância, enquanto $6 \%$ achou que o curso não teve nenhuma diferença para a região, e as justificativas para essas respostas foram:

Além de mostrar um pouco das qualidades que a região tem a oferecer, ajuda pessoas que trabalham na área, tendo assim um grau maior de conhecimento, podendo botar isso em prática, ajudando não só em casa, mas também utilizando-se do mesmo para atuação profissional. Para leigos, uma boa oportunidade de se apaixonar pelo meio agrícola e ver de fato, o quão importante essa área é e o valor correto que deve ser dada. (E 22).

Além de ser um atrativo para os jovens do campo não fazerem a retirada do interior para busca de emprego, o curso também deixa a cidade com atrativo para as pessoas de fora promovendo a vinda de novas pessoas para morar, consequentemente trabalhar e disseminar a informação para mais pessoas. (E 05).

Nossa região é basicamente mantida pela produção agropecuária, com isso a formação dos profissionais do curso é extremamente essencial para a região, para dar apoio aos produtores com a finalidade de produzir com maior quantidade e produtividade. (E 11).

Pra valorizar mais o agricultor, ajudar os agricultores que tem suas dúvidas, fazer com que as produção tenham maior rendimento. (E 19).

Prepara o jovem para entrar no mercado de trabalho local e regional. Realiza um curso em conjunto a um período em que tem a necessidade de realizar o ensino médio. (E 06).

Porque muitos jovens estão abandonando o campo é indo pra cidade onde tudo é mais difícil. Por isso seria de extrema importância um curso na nossa região para incentivar jovens produtores. (E 28).

Ao serem questionados quanto a importância do curso para a região, todos responderam que o curso acrescenta e valoriza muito a região, pois mostra as qualidades que as dimensões regionais tem a oferecer. Assim sendo, é um importante atrativo para os jovens do campo, que ao realizarem um curso em conjunto com o ensino médio poderão utilizar do mesmo para atuação profissional, e o curso também serve de alicerce para que os jovens não se retirarem do interior para buscarem emprego, evitando o êxodo rural e valorizando as culturas da região.

Pereira (2012, p. 288) nos diz que "no debate atual da educação profissional, traduzido o Plano Nacional de Educação (PNE) 2011-2020, notamos que é sob o mote da universalização do ensino médio que aparecem as primeiras referências à educação profissional.

A educação escolar, no contexto atual, é vivenciada por incontáveis modificações da sociedade moderna, que resulta do processo de globalização que instiga muitas esferas da sociedade, bem como da vida humana identificado nos fatores: 
econômicos, sociais, políticos e culturais que se ligam com a ampliação do capitalismo no estágio atual do mundo. (Libâneo, 2011).

Há também a possibilidade de preparação para o mercado de trabalho, local e regional, com oportunidade de conhecer melhor o meio agrícola e o seu valor para a comunidade, obtendo renda para sua sobrevivência e tornando da agricultura sua profissão. As vantagens se estendem, também, aos agricultores pois, elas valorizam e auxiliam na obtenção de maior qualidade e produtividade.

Os egressos ainda relataram que a região é basicamente mantida pela produção agropecuária, e com isso a formação dos profissionais do curso é extremamente essencial, pois assim estes profissionais poderão dar apoio aos produtores, com a finalidade de produzir com maior quantidade e produtividade.

Quando perguntado aos alunos se 'você trabalha na sua área de formação, como Técnico em Agropecuária', obtivemos um percentual de $18 \%$ (dezoito por cento) sobre os entrevistados. Nesse caso, constatamos que é de fato uma pequena parcela que trabalha na área, porém mesmo sem serem ativos na agropecuária, estão buscando conhecimentos e explorando esse campo de trabalho. Em decorrência disso, certamente, poderá haver um interesse significativo de prosseguir seus estudos acadêmicos no ensino superior nessa área. Sobre isso a escola aliada ao Ensino Técnico, Frigotto (2001, p. 82) ressalta que:

No campo educativo, necessitamos reiterar, sem constrangimento, a concepção de educação básica (fundamental e média) pública, laica, unitária, gratuita e universal, centrada na ideia de direito subjetivo de cada ser humano. Uma educação omnilateral, tecnológica ou politécnica formadora de sujeitos autônomos e protagonistas de cidadania ativa e articulada a um projeto de Estado radicalmente democrático e a um projeto de desenvolvimento "sustentável". (Frigotto, 2001, p. 82).

Sabe-se, no entanto, que existem muitos obstáculos no caminho que poderão impedir a continuação dos estudos no ensino superior pois muitas vezes não é acessível a todos. Portanto, é extremamente desafiante ao aluno ingressar, concluir o ensino médio técnico e posteriormente o superior.

Um caminho para este desvio está pontuado em Antoniazzi e Leal Neto (2008, p. 3), quando os autores destacam que existe a "necessidade de se repensar a educação profissional e o ensino médio sob a perspectiva da emancipação humana e não da manutenção da lógica do capital que em sua gênese é excludente, reforçando as desigualdades sociais em que o campo educacional é apenas uma de suas manifestações. “

Aos egressos que trabalham na área foi questionado: 'Você acredita que o Curso Técnico de Agropecuária Integrado ao Ensino Médio realizado na Escola Técnica Agrícola Vale da Uva Goethe lhe deu vantagens na hora da contratação do trabalho? Se sim, descreva a sua percepção sobre as vantagens obtidas'. Foram obtidas as seguintes respostas significativas.

Sim, pois apesar de ter pouca idade quando comparado aos demais candidatos ao cargo em que estou engajado, pude ser escolhido pelo diploma do curso e pelos conhecimentos que pude adquirir no momento em que o cursei. (E 10).

Não trabalho mais na área, mas logo depois da conclusão do curso, fui beneficiado pois consegue trabalho como técnico em uma casa agropecuária da região. (E 23).

Sim, na parte de assistência técnica que realizo é muito importante ter o conhecimento para passa para os clientes. (E 12).

Trabalho pra min mesmo no caso é as vantagens foram que implantei na propriedade as técnicas ministradas durante o curso. (E 15). 
As respostas obtidas foram muito compensadoras enquanto pesquisadora, mas também como ex-professora, pois foi possível constatar que o curso alcançou o objetivo de inserir o egresso no mercado de trabalho, no ramo agrícola, e/ou servir de orientação e contribuição para aplicar em sua propriedade os conhecimentos experienciados no curso. Em uma das respostas positivas, quanto a pergunta, o egresso respondeu que apesar da pouca idade, o curso foi escolhido devido ao diploma, e pelos conhecimentos que adquiriu no momento em que cursou o Curso Técnico de Agropecuária Integrado ao Ensino Médio realizado na Escola Técnica Agrícola Vale da Uva Goethe, pois conseguiu trabalho como técnico em uma casa agropecuária da região.

Outro egresso mencionou que realiza trabalhos na parte de assistência técnica, e com o Curso Técnico de Agropecuária Integrado ao Ensino Médio, realizado na Escola Técnica Agrícola Vale da Uva Goethe, conseguiu acrescentar muitos conhecimentos, os quais repassa para os seus clientes.

Um terceiro egresso revelou ser autônomo e trabalha para si mesmo. Ele destacou que, durante o curso Técnico de Agropecuária Integrado ao Ensino Médio realizado na Escola Técnica Agrícola Vale da Uva Goethe, com as técnicas adquiridas no curso, conquistou vantagens, as quais conseguiu implantar na sua propriedade.

Na sequência, ao ser perguntado 'Você está cursando curso de Graduação? Sim? Não? Se sim, a área Técnica do Curso Técnico de Agropecuária Integrado ao Ensino Médio realizado na Escola Técnica Agrícola Vale da Uva Goethe foi levada em consideração na sua escolha de área para a Graduação? Explique as motivações', podemos perceber que 58\% está cursando uma Graduação, enquanto $42 \%$ apenas terminou o ensino médio, e quanto às justificativas que impactaram, obtivemos:

Estou há quase 4 anos na graduação e ainda hoje tem coisas que me lembro do técnico que me beneficiam no entendimento mais facilitado das matérias e na prática dos trabalhos acadêmicos, que já eram praticados no curso técnico. Os professores sempre enfatizam o quanto nós (os alunos que têm técnico) somos privilegiados e o quanto vamos nos destacar no futuro por conta disso. (E 07).

Sim, sempre tive afinidade com essa área por ter nascido em família de agricultores, o técnico só me fez ter ainda mais certeza do que eu queria seguir e agora cursando agronomia continuo amando esse mundo. Caso não tivesse feito o curso poderia ter seguido uma área completamente diferente e ter tido arrependimentos em relação a carreira que fosse seguir. Sim, sempre tive afinidade com essa área por ter nascido em família de agricultores, o técnico só me fez ter ainda mais certeza do que eu queria seguir e agora cursando agronomia continuo amando esse mundo. Caso não tivesse feito o curso poderia ter seguido uma área completamente diferente e ter tido arrependimentos em relação a carreira que fosse seguir. (E 22).

Não, antes mesmo de ingressar no curso já estava decidido qual graduação iria cursar e durante a faculdade tive muitas dificuldades em relação as matérias básicas que deveriam ter sido ensinadas juntamente com o Curso Técnico. (E 16).

As respostas gerais foram compensadoras e positivas, onde os egressos revelaram que foram beneficiados com o entendimento facilitado pelas matérias e pela prática dos trabalhos acadêmicos, já que eram praticadas no curso técnico na Escola Técnica Agrícola Vale da Uva Goethe. Porém um aluno relatou que teve muitas dificuldades em relação às matérias básicas, as quais deveriam ter sido ensinadas juntamente com o Curso Técnico na Escola Técnica Agrícola Vale da Uva Goethe. 
Por fim, foi solicitado aos respondentes: Você gostaria de fazer algum depoimento sobre a Escola Técnica Agrícola Vale da Uva Goethe? e foram obtidas as seguintes respostas, que também foram incluídas ao produto educacional apresentado no próximo capítulo.

A escola técnica foi um local onde tive muitos aprendizados, mesmo no começo eu querendo desistir de estudar no técnico porém com a minha persistência aos poucos fui gostando das aulas que me trouxeram cada vez mais aprendizado que vou levar para sempre comigo e também o convívio com pessoas que eu nunca tinha visto antes onde aprendi muito e vou levar sempre comigo o carinho de todos da escola. Uma observação que queria deixar aqui é que o técnico em agropecuária não deveria ter fechado. (E 24).

Foi a melhor escola que já estudei, os professores eram os melhores, o conhecimento obtido nos 3 anos de escola técnica vão ficar gravadas por muito tempo. Escola sempre disposta a levar as novidades aos alunos e sempre inovando com ideias, não teve 1 dia na qual não tivemos um momento diferenciado, tudo era perfeito. Ficou a saudade e o conhecimento dessa escola maravilhosa. Agradeço imensamente a todos que contribuíram com esses 3 anos de caminhada. (E 09).

Conheci pessoas totalmente diferentes; personalidades diferentes, manias, jeitos e trejeitos diferentes, mas todos com um mesmo objetivo: se tornar alguém com formação na vida, ter um diploma, uma profissão. Esse mesmo objetivo nos uniu por 3 anos, e nos ensinou o verdadeiro significado do cooperativismo e engrandecimento pessoal. Se eu pudesse recomendaria a todos que estão passando ou vão passar ainda pelo ensino médio, para complementar fazendo o técnico junto, é conhecimento e experiência de vida. (E 19).

No geral os "profissionais" da educação, não eram tão profissionais. Íamos a viagens práticas e essas viagens com praticamente 5 ou 6 horas de duração eliminavam 4 a 5 aulas de disciplinas importantes, como: Física e matemática. Enfim, até hoje tenho muita dificuldade nas áreas de exatas graças às fracas aulas, e as poucas aulas, porque acredito que metade das aulas de exatas eram arrematadas, com viagens muitas vezes sem ter nexo algum com a disciplina. Mas sim, tínhamos alguns professores muito bons, que até hoje mantenho contato. Muitos alunos se esforçavam para serem aprovados, outros não faziam nada, exatamente nada, em 3 anos que cursei não vi nenhuma reprovação, então concluímos que alunos que se esforçavam passavam, e os que não se esforçavam também eram aprovados. (E 21).

Acredito que a ideia de ter uma Escola Técnica na região é sim importante porém só é válida se realmente for realizada de forma correta visando a real educação dos seus alunos, com ensino forte e condizente com o título de formação. A maioria dos alunos que cursaram o curso técnico não conseguiram passar em vestibular ou acompanhar o ensino da graduação e também não se sentem preparados para trabalhar na área de Técnico em Agropecuária, então a função do curso não foi atendida de forma integral. (E 33).

Entre as respostas positivas, em relação ao curso técnico, relatamos a fala de um egresso, onde ele descreve que foi um local de aprendizados, que "levaremos para a vida" (E 17). Tiveram a oportunidade de estudar e concluir o "melhor curso na melhor escola com melhores e os mais dedicados professores" (E 28). Segundo ele a escola sempre apresentou novidades aos alunos com inovação de ideias, momentos diferenciados, socialização, que foram divididos em: cooperativismo, engrandecimento, conhecimento e experiência de vida.

Outro egresso relatou que considerou fraco o ensino de disciplinas importantes como: física e matemática e que, até hoje, tem déficit de aprendizagens pelos conteúdos insuficientes que recebeu. 
Uma terceira opinião revelou que, a maioria dos alunos que cursou o curso técnico, não conseguiu passar em vestibular ou acompanhar o ensino da graduação, e também não se sentem preparados para trabalhar na área de Técnico em Agropecuária, então a função do curso não foi atendida de forma integral.

Destacamos, também, a opinião de um aluno que descreveu o seguinte sobre o curso:

No papel a ideia de uma escola técnica parece muito proveitosa para a região e para os estudantes, mas na prática se mostrou bastante falha. Ofereceu um ensino médio pobre nas matérias básicas, mesmo tendo um adicional do técnico. $O$ ensino técnico trouxe conhecimentos que não seriam obtidos em um ensino médio comum, mas se comparado a uma escola técnica de verdade o ensino foi muito pobre, tanto em horas, profissionais e materiais abordados, tornando o técnico formado muito inferior a outros profissionais de outras escolas. O ensino médio é o principal ponto fraco, pois além de uma carga horária menor, o período de aula formado apenas com uma disciplina se mostrou bastante inferior ao praticado em escolas estaduais por exemplo, pois o tempo perdido em uma noite com atividades que consumiam boa parte da aula, mais o tempo de atraso para o professor conseguir achar uma forma de ensinar uma turma totalmente heterogênea consumia muitas vezes o período todo, atrasando conteúdos que nunca foram abordados. O principal ponto falho foi o calendário espremido, muito mais que uтa escola padrão, onde vários assuntos muito importantes não foram abordados ou apenas pincelados, seja por falta de tempo ou por mau administração deste, o que gerou uma lacuna gigantesca que um ensino médio não poderia ter, a base deveria ser muito mais importante que o bônus oferecido de técnico. Para resumir os 3 anos de curso, posso dizer que foi um técnico pobre com um ensino médio muito fraco, onde técnico não mudou nada em minha vida e a falta de um ensino médio fez eu ter maiores dificuldades em minha vida acadêmica e pessoal. Para a região pouco mudou, a maioria dos técnicos não atuaram na área e continuaram trabalhando em suas casas e me atrevo a dizer que de forma igual a antes do curso, muitos que queriam vida acadêmica acabaram por desistir por se frustrarem na academia ou por não conseguirem uma boa nota no vestibular, como disse, por ter um ensino médio pobre. A prefeitura que quis buscar um incentivo ao estudo só obteve um aumento grande no seu orçamento anual. (E15).

Diante do que o egresso comentou, foi observado que, para ele, para o professor conseguir ensinar uma turma totalmente heterogênea consumiria muitos períodos, atrasando conteúdos que nunca foram abordados. O principal ponto falho foi o calendário espremido. Vários assuntos importantes foram apenas pincelados. Para resumir os 3 anos de curso foi um técnico pobre com um ensino médio fraco, onde o técnico não mudou nada sua vida.

Tive dificuldades acadêmicas e pessoais por conta disso muitos que queriam vida acadêmica acabaram desistindo por se frustrarem e não conseguirem boa nota no vestibular. A prefeitura tentou proporcionar um incentivo ao estudo mas só obteve aumento no seu orçamento anual sem retornos concretos. (E 10).

Super (1955) foi uma das primeiras pessoas a recomendar uma concepção na alternativa na questão profissional, tendo como suporte conceitos como maturidade, interesses e valores, que indicam um processo de evolução e desenvolvimento.

Quando fazemos relação entre a escolha da aptidão e/ou preferência particular, onde há uma maior predominância entre os respondentes. Romanelli (1995) explica que a razão de uma pessoa decidir por determinada carreira é o fato de estarem preocupados com sua profissionalização futura, pois o sujeito busca obter novos conhecimentos e competências, para 
poder ajustar-se ao mercado de trabalho, onde a satisfação pessoal e a realização profissional estão em segundo plano, mas existe outro eixo articulador que é a vocação, que para o sujeito tem um valor próprio, pois este está em primeiro lugar quanto a satisfação pessoal.

Segundo Bohoslavsky (1977, p. 48-49) o adolescente procura, em sua escolha profissional, "a realização pessoal, a felicidade, a alegria de viver". A mesma opinião é compartilhada por Castanho (1988, p. 10); "Quando alguém procura uma profissão, busca algo que o faça feliz".

Sabemos que o ensino técnico profissionalizante foi consolidado após a Segunda Guerra, tendo características semelhantes ao que é ofertado atualmente. Assim, no conhecido "Ensino Novo", Getúlio Vargas destaca o valor devido ao Ensino Profissional, através do art. 129 da Carta Magna, que estava em vigor à época, que segue:

O ensino pré-vocacional e profissional destinado às classes menos favorecidas é, em matéria de educação, sendo o primeiro dever do Estado. Cumpre-lhe dar execução a esse dever, fundando institutos de ensino profissional e subsidiando os de iniciativa dos Estados, dos Municípios e dos indivíduos ou associações particulares e profissionais. É dever das indústrias e dos sindicatos econômicos criar, na esfera de sua especialidade, escolas de aprendizes, destinadas aos filhos de seus operários ou de seus associados. A lei regulará o cumprimento desse dever e os poderes que caberão ao Estado sobre essas escolas, bem como os auxílios, facilidades e subsídios a lhes serem concedidos pelo poder público. (Brasil, 1937).

Consideramos relevantes todas as colocações, a respeito do Curso Técnico em Agropecuária da Escola Técnica Agrícola Vale da Uva Goethe, pois cada egresso tem uma expectativa, uma visão e um objetivo a alcançar. Alguns já trazem consigo uma vasta bagagem de conhecimentos empíricos e/ou uma inclinação para aquela atividade proposta. Percebe-se que alguns realmente se enquadraram na dinâmica do curso e, ficaram satisfeitos com o que aprenderam. Outros, porém, desejam ir mais além do trivial e buscam explorar os conhecimentos de forma mais profunda.

Vivemos em uma sociedade democrática e diversificada onde as diferenças não mais nos separa e sim aproxima. Analisando os depoimentos de forma impessoal e imparcial, considera-se que em todos foram observados a verdade e coerência, dentro da sua realidade e sua bagagem de vida e memória.

\section{Algumas Considerações Finais}

A oferta do Curso Técnico Integrado ao Ensino Médio tem como objetivo, principalmente, o ingresso do jovem ao mercado de trabalho de forma qualificada e dirigida para uma certa área de atuação. No caso do Curso Técnico em Agropecuária da Escola Técnica Agrícola Vale da Uva Goethe, a qualificação se dirige ao ramo agropecuário, pois a população local que é constituída, em sua maioria, de pequenos produtores tanto para subsistência, como pequenos fornecedores locais de produtos agropecuários do setor primário.

Delimitou-se como palavras-chave desta pesquisa a Educação Profissional e Tecnológica, Aluno Egresso, Curso Técnico em Agropecuária e as argumentações realizadas a respeito da Educação Profissional foram relevantes para a construção e análise da importância que o Curso Técnico em Agropecuária da Escola Técnica Agrícola Vale da Uva Goethe representou para os egressos e, como a comunidade se beneficiou dos conhecimentos adquiridos nesse curso, pois o mesmo, apresentou aos seus estudantes técnicas que vão ajudar no cultivo do solo, proporcionando mais produtividade com mais qualidade nas colheitas. Dessa forma, o curso técnico além de valorizar o cultivo local, fixa seus conterrâneos em sua localidade, oferecendo oportunidade de trabalho no seu lugar de origem evitando assim o êxodo rural que levam a decadência e a desocupação local.

Sabe-se que o curso ofereceu uma matriz curricular atrativa, dinâmica e atualizada, com foco na preparação para o mundo de trabalho. Ao concluir o Curso Técnico em Agropecuária Integrado ao Ensino Médio da Escola de Educação Técnica 
Vale da Uva Goethe o egresso, além da sua vivência e experiências adquiridas no convívio familiar e social, acumulou uma bagagem de conhecimentos específicos repassados por profissionais qualificados e aptos para repassar informações indispensáveis para a formação técnica.

No Ensino Médio Integrado percebemos que o jovem, que tem uma visão futurista da sua vida profissional, já possui a compreensão de que o curso irá lhe proporcionar conhecimentos e a iniciação necessária para atuar no mercado de trabalho e, principalmente, compreender os movimentos inerentes ao mundo do trabalho. De posse dos conhecimentos adquiridos no curso técnico, este aluno agregará ao seu currículo um diferencial e uma especialização na área, de agropecuária, como curso profissionalizante.

Com a pesquisa, percebemos que a escolha das profissões ocorre de diversas formas e os cursos técnicos nem sempre levam o egresso a seguir seus estudos, em nível superior, pela mesma linha do curso técnico. Por diversas razões muitas vezes a vida acadêmica do egresso percorre outro caminho, que não foi abordado no curso técnico cursado, onde dentre vários fatores influenciadores podemos citar: a realidade em que a pessoa se encontra inserida para se projetar no campo de trabalho, opiniões de pessoas próximas e influentes como familiares e, também poderá ocorrer mudanças de ramo e atuação motivados por planos de carreiras e remuneração.

A escolha que leva ao sucesso profissional nem sempre ocorre de forma sequencial. Muitos fatos contraditórios poderão ocorrer e mudar completamente a ótica e, poderá contribuir e servir de base para o foco da profissão escolhida e, é nessa fase que o curso técnico desempenha seu melhor papel de norteador e esclarecedor, servindo como base para a profissão.

Ressalta-se que o curso técnico, por si só, não remeterá ao sucesso profissional, fazendo necessário interesse, dedicação, empenho e continuidade para um bom desenvolvimento e colocação na prática dos conhecimentos adquiridos no curso. Partindo do pressuposto de que uma grande demanda de egressos não consegue dar continuidade aos seus estudos no nível superior, entende-se a importância do curso técnico, no futuro e, na vida profissional dos concluintes como possibilidade de qualificação para o trabalho.

O jovem que faz opção pelo curso técnico faz uma aposta no seu futuro buscando uma profissão na qual julga ter vocação e aptidão para colocar em prática os conhecimentos que adquiriu no curso em preparação para o trabalho.

Como conclusões considera-se indispensável ouvir a opinião dos egressos acerca dos impactos decorrentes da trajetória durante o curso. Sabemos que as opiniões seriam diversificadas, pois cada egresso possui uma aptidão e um interesse individual. Portanto, pode-se resumir, segundo suas respostas, que aqueles que se identificaram com a essência, objetivo e proposta do curso, ficaram satisfeitos com os conhecimentos que adquiriram, sendo que alguns, inclusive, exercem as atividades agrícolas e agropecuárias, e até ingressaram na vida acadêmica do ensino superior na mesma área. Poucos são os relatos de alunos que não se identificaram em nada com o curso e, por isso considerou que o curso nada acrescentou em sua vida.

Analisando de uma forma global as respostas foram motivadoras, onde a maioria relatou estarem satisfeitos com os conhecimentos adquiridos, e também com a equipe de professores, ou seja, o curso e a escola cumpriu, na íntegra, o objetivo para o qual foi proposto.

Destaca-se, como possibilidade de trabalhos futuros a execução de pesquisas de mesma natureza para outras áreas de cursos técnicos.

\section{Referências}

Altmann, R. (2010). Perspectivas para a agricultura familiar. Florianópolis: Horizonte.

Antoniazzi, M. R. F., \& Leal Neto, A. A. V. (2008). Educação profissional integrada ao ensino médio: concepção e políticas no governo Lula. Anped 31r.

Barbosa, G. J. (2010). Técnico Agrícola: um século de profissão. http://www.fenata.com.br/site/index.php. 
Research, Society and Development, v. 10, n. 9, e1691099269, 2021

(CC BY 4.0) | ISSN 2525-3409 | DOI: http://dx.doi.org/10.33448/rsd-v10i9.9269

Bohoslasvsky, R. (1993). Orientação vocacional: a estratégia clínica: Martins fontes.

Camarano. A. C. (2006). Envelhecimento da população brasileira: uma contribuição demográfica: Guanabara Koogan.

Ciavatta, M., \& Rummert, S. M. (2010). As implicações políticas e pedagógicas do currículo na educação de jovens e adultos integrada à formação profissional. Educ. Soc., Campinas, 31(11). http://www.cedes.unicamp.br

Constituição dos Estados Unidos do Brasil de 10 de Novembro de 1937. https://presrepublica.jusbrasil.com.br/legislacao/92067/constituicao-dos-estadosunidos-do-brasil-37\#art-129

Frigotto, G. (2001). Educação e trabalho: bases para debater a Educação Profissional emancipadora. Perspectiva, Florianópolis, 19(1).

Frigotto, G. (2007). A relação da educação profissional e tecnológica com a universalização da educação básica. Edu. Soc., Campinas, vol.28, n.100. http://www.cedes.unicamp.br

Gatti, B. (2004). Estudos quantitativos em educação. Educação e Pesquisa. São Paulo, 30(1).

Kuenzer, A. Z. (2000). O ensino médio agora é para vida: entre o pretendido, o dito e feito. Educação \& Sociedade, $\mathrm{n}^{\circ} 70$. www.scielo.br/pdf/es/v21n70/a03v2170.pdf

Libâneo, J. C. (2011). Didática e o Trabalho Docente: a mediação didática do professor nas aulas. In: Libâneo, J. C., Suanno, M. V. R., \& Limonata, S. V. (Orgs.). Concepções e práticas de ensino num mundo em mudança: diferentes olhares para a Didática. Goiânia: CEPED/Editora PUC Goiás

Lima, L. C. (2000). Organização Escolar e Democracia Radical: Paulo Freire e a Governação da Escola Pública. S. Paulo: Instituto Paulo Freire e Cortez Editora.

Oliveira, R. (2009). Possibilidades do Ensino Médio Integrado diante do financiamento público da educação. Educ. Pesqui. [online]. 35(1). https://www.scielo.br/scielo.php?script=sci_arttext\&pid=S1517-97022009000100004\&lng=pt\&tlng=pt

Pasqualli R., Silva V. D., \& Silva A. L. D. (2019). Limites e potencialidades de materialização do currículo integrado: uma análise dos planos de ensino e diários de classe. Revista Contexto \& Educação, 34(109), 104-120. https://www.revistas.unijui.edu.br/index.php/contextoeducacao/article/view/7631

Pereira, I. B. (2012). Educação Profissional. In: Caldart, R. S., et al (orgs.). Dicionário da educação do campo. Rio de Janeiro, São Paulo: Escola Politécnica de Saúde Joaquim Venâncio, expressãopopular.

Romanelli, G. (1995). O significado da educação superior para duas gerações de famílias de camadas médias. Revista Brasileira de Estudos Pedagógicos, Brasília, 76(184).

Viella, M. D. A. L., Mendes, W. G., \& Pasqualli, R. (2020). Egressos dos cursos técnicos em Agropecuária: análise das produções acadêmicas. Research, Society and Development, 9(10), e7959109242. https://doi.org/10.33448/rsd-v9i10.9242

Yin, R. K. (2016). Pesquisa qualitativa do início ao fim. Porto Alegre: Penso. 